\title{
Kaplan-Meier analysis of Greek and Roman coinage production
}

\author{
FRANCIS ALBAREDE ${ }^{1}$, FRANÇOIS DE CALLATAŸ ${ }^{2}$, \\ PIERLUIGI DEBERNARDI ${ }^{3}$ AND JANNE BLICHERT-TOFT ${ }^{1}$ \\ ${ }^{1}$ Ecole Normale Supérieure de Lyon \\ ${ }^{2}$ Bibliothèque Royale \\ ${ }^{3}$ INT \\ Presenting Author: albarede@ens-lyon.fr
}

Monetary output of ancient powers such as Athens and Rome is usually inferred from die statistics of monetary issues and from mine production. More than 20 statistical methods have been proposed so far for this task, but we are here proposing a different approach based on a survival analysis of dies. The present work applies a Kaplan-Meier analysis of resistance to failure to 27 sets of well-documented monetary issues. The failure rate function assumes a U-shaped form known in reliability engineering literature as the 'bathtub curve'. With the geometric distribution of die failure being demonstrably violated for a large fraction of the data sets, the die distribution of each data set was instead fitted by a mixture of two Weibull distributions corresponding to two failure regimes. Dies can be divided into bad dies, failing early for various reasons ('infant mortality'), and good dies, failing late by fatigue. The dual populations reflect the efforts of the blacksmiths at the time to produce bronze dies that would meet two conflicting needs: the reduction of infant mortality and the limitation of ductile deformation during minting. The variable proportions of the two populations suggest that not all workshops had fully mastered die technology with some visible evolution from the Greeks to the Romans. While the magic bronze composition, corresponding to a $\mathrm{Cu}-\mathrm{Sn}$ peritectic composition with $22 \% \mathrm{Sn}$, clearly was known to ancient metallurgists around the Mediterranean, how well tempering, which would have strongly affected die lifetimes by allowing controlled spinodal decomposition, was understood is uncertain but was a critical factor of mint productivity. Because of the dichotomy induced by contrasting mechanical properties, corrections for missing dies based on singletons and causes of die failure must be carefully assessed for each data set. 